\title{
23. Social justice and human rights: using Indigenous socioeconomic data in policy development
}

\section{Tom Calma}

The perspective that I intend to bring to this discussion is a human rights one. I want to reflect on the importance and utility of Indigenous socioeconomic data in contributing to improved enjoyment of human rights by Indigenous peoples in Australia.

Generally speaking, in Australia we have not converted our international human rights obligations into domestic law and practice very well. This is particularly the case in relation to economic, social and cultural rights, such as the right to health, housing, education and so forth. As a result, human rights standards do not enjoy prominence as a tool in planning policy or in holding governments accountable in Australia.

Despite this, there are significant developments occurring in the human rights system worldwide which demonstrate the suitability of a human rights framework for advancing policy development and which ultimately can guide improvements in Indigenous socioeconomic outcomes.

What I intend to do today is to identify some recent developments at the international level relating to human rights and outline a human rights framework for addressing Indigenous socioeconomic status. I will then consider this in light of recent developments in Indigenous policy making in Australia, and make some comments about:

- the adequacy of existing processes for assessing Indigenous socioeconomic outcomes

- how these processes relate to Australia's human rights obligations and how adequate they are in holding governments accountable for the commitments they have made through the COAG, as well as through the new arrangements at the federal level, and

- future directions for data collection and the identification of research priorities for analysing Indigenous socioeconomic outcomes from a human rights and social justice perspective. 


\section{Recent international developments - the human rights context}

I want to begin at the international level. Recent years have seen significant discussion at the United Nations (UN) on how to better integrate human rights into its everyday activities. There are currently three main, inter-related developments.

Firstly, there is the focus on the need to reform the operations of the UN itself. Debate on this issue is currently focused around the report by Kofi Annan, the Secretary-General of the United Nations, which is titled, In Larger Freedom: Towards Development, Security and Human Rights for All.

This report proposes some radical change to the structures of the UN, from the Security Council through to replacing the Commission on Human Rights. The report will form the basis of the summit of world leaders taking place in New York in September this year. The Summit will assess progress five years down the track in implementing the UN Millennium Declaration and in meeting the targets set in the declaration, known as the Millennium Development Goals.

The report of the Secretary-General is focused on achieving better integration of the purposes of the UN as laid down in the UN Charter-namely, peace and security, development, and human rights. As the Secretary-General's report (Annan 2005: para 17) states:

Humanity will not enjoy security without development, it will not enjoy development without security, and it will not enjoy either without respect for human rights. Unless all these causes are advanced, none shall succeed.

The report proposes a speeding up of a process that has been underway for at least the past decade; of integrating human rights into the everyday operations of the UN. The process is being termed 'mainstreaming'. It envisages a significantly expanded role for the Office of the High Commissioner for Human Rights, as well as making human rights issues central across all areas of UN activity, with a particular focus on the rule of law, democratic processes and addressing extreme poverty.

The second development is the increased focus and commitment of the UN on poverty eradication. This is exemplified by the Millennium Development Goals ${ }^{1}$ and the commitments of all governments to achieve these goals by the year 2015 .

1 The goals are: eradicate extreme poverty and hunger; achieve universal primary education; promote gender equality and empower women; reduce child mortality; improve maternal health; combat HIV/AIDS, malaria and other diseases; ensure environmental sustainability; and develop a global partnership for development. 
The focus of these goals is very much centred on developing nations. The usual context in which the involvement of countries like Australia is discussed is in relation to international aid, technical assistance and debt relief. But the implications of this focus on poverty eradication clearly relate to the situation of Indigenous peoples in Australia.

As part of the UN reform process, a large part of the focus on integrating human rights into UN activities more generally has been on improving the human rights system. In her report to the UN General Assembly for the upcoming summit in September 2005, the High Commissioner for Human Rights (Louise Arbour) has set out how she envisages the human rights system can be used to address the challenge of poverty eradication. Her comments are directly relevant to the challenges in improving Indigenous socioeconomic outcomes in Australia. Arbour (2005) states:

We will focus on promoting rights-sensitive poverty reduction strategies and the application of rights-based approaches to development, and advancing the right to development. In doing so, we will emphasise the free, active and meaningful participation of rights holders, the accountability of duty bearers, non-discrimination at all levels and the political and economic empowerment of those that development seeks to lift out of poverty. In addition, we will use the human rights framework to buttress and solidify pledges made by the richer countries.

Significant work has already commenced with the purpose of elaborating the linkages between human rights, poverty eradication and development. Past social justice and native title reports have highlighted this work, such as the extensive focus on human rights by the United Nations Development Programme (UNDP) (including through its annual Human Development Reports), increased focus on the right to development, and also through the drafting of guidelines on human rights and poverty eradication by the High Commissioner for Human Rights and the UNDP. I will refer to this work in more detail shortly.

The third development internationally, which complements these issues, is that we are also facing an increased level of consideration of issues specifically relating to Indigenous people in the UN system. This is very much a result of the inaugural four years of work of the Permanent Forum on Indigenous Issues. This forum, to which Mick Dodson was elected as the representative of the Indigenous peoples of the Pacific region last year, has been very successful in highlighting the plight of Indigenous peoples at the highest levels of the UN.

At its fourth session earlier this year, for example, the forum considered the application to Indigenous peoples of the Millennium Development Goals relating to the provision of universal primary education and the eradication of extreme poverty. In its report to the Economic and Social Council, the forum stated that 
'Indigenous and tribal people are lagging behind other parts of the population in the achievement of the [Millennium Development Goals]...in most, if not all, the countries in which they live' and called for greater attention to the situation of Indigenous peoples (Permanent Forum on Indigenous Issues 2005: paras 4-6). Indigenous peoples from so-called 'first world' countries such as the United States of America, Canada and Australia have consistently voiced their concerns at the Permanent Forum about the extent of poverty and marginalisation in their communities and the need for increased international attention to this situation. In doing so, they have challenged the traditional focus of UN activity being solely on the developing world.

The Permanent Forum has also led developments in the UN to improve systems for collecting and disaggregating data relating to Indigenous peoples at the international level. In January 2004 they convened an international workshop on data collection and disaggregation for Indigenous peoples (Permanent Forum on Indigenous Issues 2004). This workshop identified the need for full participation of Indigenous peoples in all stages of data collection and analysis as an essential component of emerging participatory development practice.

So what does all of this mean?

The main point to take from this overview is that we are seeing a significantly increased focus in the UN system on the situation of Indigenous peoples and on poverty eradication and development as human rights issues. The normative frameworks of the human rights system are being increasingly applied to these issues.

As a result, there is increased attention to how governments go about addressing poverty within their borders, as well as how they participate in international cooperation efforts, and increased scrutiny of government's performance on these issues. For Australia, this has the following implications:

- Firstly, we can expect that the 'Achilles heel' that is the poor performance of successive Australian governments in addressing Indigenous marginalisation will receive increasing attention internationally and this attention will broaden in its focus as human rights approaches to poverty and development become 'mainstreamed' across the international system.

- Secondly, we can expect greater scrutiny of our policy approaches to addressing poverty and development among Indigenous peoples as a matter of compliance with our human rights obligations.

\section{A human rights approach to assessing Indigenous socioeconomic outcomes}

So, then, what does a human rights approach to assessing Indigenous socioeconomic outcomes entail? 
A rights-based approach includes the following elements:

- it emphasises the accountability of governments for socioeconomic outcomes among different sectors of civil society by treating these outcomes as a matter of legal obligation, to be assessed against the norms established through the human rights system

- it emphasises the process for achieving improvements in these outcomes, with the free, active and meaningful participation of affected groups being critical. There is emerging - through international law - a broader acceptance of this under the heading of free, prior and informed consent

- it establishes fundamental principles to guide policy development (e.g. that disadvantaged groups should not be discriminated against and should be treated equally), and

- it requires governments, working in partnership with affected groups, to demonstrate that they are approaching these issues in a targeted manner, and are accountable to the achievement of defined goals within a defined timeframe.

This latter point is known as the 'progressive realization' principle. This principle is set out in Article 2 of the International Covenant on Economic, Social and Cultural Rights. This is one of the main international human rights treaties to which Australia is a party.

Article 2 (1) of the covenant requires Australia: to take steps '...to the maximum of its available resources, with a view to achieving progressively the full realization of the rights recognised in the present Covenant by all appropriate means' (emphasis added).

The committee overseeing the covenant has commented that while the obligation 'to take steps' means that the full realisation of relevant rights may be achieved progressively, the taking of such steps cannot be delayed and, further, those steps should be deliberate, concrete and targeted as clearly as possible towards meeting the obligations recognised in the covenant (Committee on Economic Social and Cultural Rights 2004: para 2).

The High Commissioner for Human Rights has described this principle and its relevance to policy making as follows:

Since the realization of most human rights is at least partly constrained by the availability of scarce resources, and since this constraint cannot be eliminated overnight, the international human rights law explicitly allows for progressive realization of rights... While the idea of progressive achievement is common to all approaches to policy making, the distinctiveness of the human rights approach is that it imposes certain 
conditions on the behaviour of the State so that it cannot use progressive realization as an excuse for deferring or relaxing its efforts. ${ }^{2}$

Accordingly,

The idea of progressive realization has two major strategic implications. First, it allows for a time dimension in the strategy for human rights fulfillment by recognizing that the full realization of human rights may have to occur in a progressive manner over a period of time. Second, it allows for setting priorities among different rights at any point in time since the constraint of resources may not permit a strategy to pursue all rights simultaneously with equal vigour (High Commissioner for Human Rights 2004: 22).

This approach requires that governments identify appropriate indicators, in relation to which they should set ambitious but achievable benchmarks, so that the rate of progress can be monitored and, if progress is slow, corrective action taken. Setting benchmarks enables government and other parties to reach agreement about what rate of progress would be adequate. Such benchmarks should be:

- $\quad$ specific, time-bound and verifiable

- set with the participation of the people whose rights are affected, to agree on what is an adequate rate of progress and to prevent the target from being set too low, and

- reassessed independently at their target date, with accountability for performance (UNDP 2000: 101).

My predecessor, as Social Justice Commissioner, has elaborated on this rights-based approach in the context of addressing Indigenous disadvantage. In particular, he identified five integrated requirements that need to be met to integrate a human rights approach into redressing Indigenous disadvantage and to provide sufficient government accountability. These requirements are:

- making an unqualified national commitment to redressing Indigenous disadvantage

\footnotetext{
2 See Hunt, Osmani \& Novak (2004: paras 19-20). These conditions are: 'First, the State must take immediate action to fulfill any rights that are not seriously dependent on resource availability. Second, it must prioritize its fiscal operations so that resources can be diverted from relatively non-essential uses to those that are essential for the fulfilment of rights that are important for poverty reduction. Third, to the extent that fulfilment of certain rights will have to be deferred, the State must develop, in a participatory manner, a time-bound plan of action for their progressive realization. The plan will include a set of intermediate as well as long-term targets, based on appropriate indicators, so that it is possible to monitor the success or failure of progressive realization. Finally, the State will be called to account if the monitoring process reveals less than full commitment on its part to realize the targets'.
} 
- facilitating the collection of sufficient data to support decision-making and reporting, and developing appropriate mechanisms for the independent monitoring and evaluation of progress towards redressing Indigenous disadvantage

- adopting appropriate benchmarks to redress Indigenous disadvantage, negotiated with Indigenous peoples, State and Territory governments and other service delivery agencies, with clear timeframes for achievement of both long-term and short-term goals

- providing national leadership to facilitate increased coordination between governments, reduced duplication and overlap between services, and

- ensuring the full participation of Indigenous organisations and communities in the design and delivery of services (UNDP 2000: 93).

The Council for Aboriginal Reconciliation's (CAR's) final report to Parliament, Australia's Challenge also commends this approach. Recommendation 1 calls on:

...the Council of Australian Governments to agree to implement and monitor a national framework for all governments and ATSIC to work to overcome Indigenous disadvantage through setting benchmarks that are measurable, have timelines, are agreed with Indigenous peoples and are publicly reported (CAR 2000).

To date, this recommendation has not been fully implemented.

\section{Recent developments in Indigenous policy in Australia}

So, let me now turn to the situation in Australia and apply this approach. We have just seen the first twelve months of what are generally referred to as the 'new arrangements' for the administration of Indigenous affairs at the federal level. This has involved:

- the abolition of ATSIC

- the transfer of Indigenous-specific programs to mainstream government departments and their continuation alongside mainstream programs

- the creation of a central OIPC with regional ICCs which are intended to deliver services on a whole-of-government basis

- the introduction of direct negotiation with Indigenous communities or sections of communities through SRAs

- the proposed introduction of regional agreement-making processes, to be known as Regional Participation Agreements, and

- $\quad$ stronger leadership within the mainstream of government with their oversight by a ministerial taskforce and a working group of secretaries of government departments.

I have discussed these new arrangements at length in the Social Justice Report 2004 and also indicated in that report how my office will continue to monitor 
them over the coming years. In my forthcoming Social Justice Report, which should be released in the latter part of this year, I am focusing on the SRA process, issues relating to representation and participation of Indigenous peoples in these new arrangements post-ATSIC, and the links between a rights-based approach to Indigenous health and the new arrangements.

The new arrangements are supplemented by commitments at the inter-governmental level through the COAG. Through successive communiqués on reconciliation and Indigenous affairs since 2000, COAG has committed to:

- $\quad$ eight trials of whole-of-government activity in Indigenous communities

- the development of a whole-of-government reporting framework on Indigenous disadvantage with biennial reports on progress, and

- a series of principles for service delivery to Indigenous communities.

The new arrangements and the COAG commitments are also now beginning to be fused together with the signing of bilateral agreements on Indigenous affairs between the Commonwealth and States or Territories. At this time, there is only one agreement formally in place, with the Northern Territory. However, it is expected that other agreements will follow in the coming months. These agreements, I understand, will build on the COAG commitments and see the relevant State or Territory agree to work with the Commonwealth on its new arrangements and in identified priority areas.

Overall, these changes are large in scope and ambitious. I remain of the view that there is still a lack of information about the new approach among Indigenous peoples and communities, and significant challenges to ensure that Indigenous communities can participate fully in these processes, and also do so equitably. It is clear that it will take several years before the new arrangements are fully in place.

\section{Implications for data collection and research}

Any assessment of the new arrangements needs to acknowledge their evolving nature. In doing so, it must be said that they raise many challenges for policy makers, Indigenous communities and researchers in how we assess Indigenous socioeconomic outcomes.

Up front, it must be said that the new arrangements involve the making of significant commitments to Indigenous peoples and communities. They are based on the idea of 'matched up' government or whole of government activity. In theory, this can deliver substantial benefits to Indigenous people. These benefits may include improving the accessibility and use of mainstream services and, accordingly, potentially opening up wider sources of funding. Or they might include simplifying administrative processes for communities in their dealings 
with government, to provide more sustained funding processes and better target actual need in communities.

The rhetoric of the new arrangements addresses many of the significant concerns that have been raised in successive reviews and reports, including that of the Commonwealth Grants Commission on Indigenous funding. These new arrangements are also matched by substantial commitments through COAG to address Indigenous disadvantage.

But what is trying to be achieved is hard work and it also has to be acknowledged that it could go wrong. While there is still no formal evaluation of the COAG trials, for example, we know that these trials cannot possibly be replicated nationally due to their resource-intensive nature. Whole-of-government activity is also notoriously difficult and potentially very expensive. If not done well, it could result in greater administrative costs and processes, cost and blame-shifting between jurisdictions and within government, a blurring of responsibilities, and a lack of transparency about process and outcomes.

The new arrangements also involve the rejection of using representative Indigenous structures to interface with Indigenous peoples and communities and proposes a model of direct engagement by government through agreement-making processes. This is not the preferred model of many Indigenous people and it is untested to date. We also do not know how this aspect of the new arrangements will work, and if it is not implemented from a community development/capacity development perspective, then sustainable and tangible outcomes may not be achieved.

\section{So the 3.1 billion dollar question is: how will we know whether the new arrangements are delivering improved outcomes or not?}

Outcomes for the period since the new arrangements have been in place will not show up in data collections and analysis for at least another two to four years. We are unlikely to see analysis of the 2006 Census until 2007 or 2008, and analysis of the next NATSISS until at least 2008. The latest report on overcoming disadvantage by the SCRGSP that was released in July this year reflects on data that pre-dates the new arrangements on most indicators. So it will not be until 2007 that we see any data which is compiled in accordance with the commitments of COAG and reported in a holistic manner that relates to the new arrangements.

It also remains to be seen how governments at all levels will link their programs and activities to achieving improvements in the headline indicators and strategic change indicators contained in the COAG reporting framework on Indigenous disadvantage.

There is also a disaggregation issue. It is not easy to manipulate current data to identify regional trends and variations. Given the reliance of the new 
arrangements on regional approaches, with coordination through regional ICC offices, the proposed use of Regional Participation Agreements for structuring regional representation and priority setting, and the continuation of COAG trials in select regions, being able to disaggregate to this level is very important for being able to establish the success or otherwise of the new approach.

And in terms of the intended focus of the new arrangements on increasing the accessibility of mainstream services for Indigenous people and communities, there is currently not even any way to identify what mainstream funding is being expended on Indigenous issues. If we cannot even say what services are or are not being utilised then we certainly cannot assess whether the services provided are culturally appropriate, accessible, available or adapted.

By the way, these latter terms - appropriate, available, accessible and adapted - have specific meanings within a human rights framework which have been elaborated in relation to the right to the highest attainable standard of health, housing, education and so forth. ${ }^{3}$ They can be used to structure analysis on the adequacy of programs to address economic, social and cultural rights. When you add these concepts to that of progressive realisation and benchmarking, you can see how a human rights approach can offer a powerful, structured and targeted approach to these issues.

What these factors indicate to me is that it is not going to be easy for us to establish what works and what does not in the new arrangements, nor to identify the impact of these processes on Indigenous socioeconomic outcomes. This will particularly be so at the regional and sub-regional level.

A related issue here is how SRAs will link to existing data collection. This is not clear at present, although the SRA approach is a staggered one with initial agreements intended to be single issue/simple agreements and forthcoming agreements intended to be more holistic and integrated in their focus.

Now, in saying this, I am identifying the challenges that lie ahead and hoping to promote informed discussion about ways to address this. What I have said is not just for the sake of it.

There is movement to address some of these issues from the government. One of the most interesting processes currently underway in relation to these issues is the Australian Government Indigenous Management Information System (AGIMIS) project. The OIPC describes this project as follows:

The main objective of the AGIMIS Project is to develop an Indigenous management information system. This will assist to support the long-term policy, program implementation and reporting requirements of the "joined

3 See, for example, the General Comments of the Committee on Economic, Social and Cultural Rights (2004). 
up', whole of government approach to Indigenous funding, program performance monitoring and reporting.

The AGIMIS Project will collect data and provide reports to monitor investment by Government, initially on Indigenous-specific activity and at a later stage on mainstream services accessed by Indigenous people. The information will allow input to the measurement of overall outcomes and the assessment of effectiveness and efficiency of programs. ${ }^{4}$

As I understand this project, it involves establishing a database that can ultimately identify what programs are active in what communities, what services they are providing, and so on. It will draw data down from existing systems maintained by individual agencies and departments. And, ultimately, it will include a mix of information about Indigenous-specific services - the initial focus of the project - and, later on, mainstream services.

The prime challenge for this project is consistency and compatibility of data. The potential, however, is a powerful tool for identifying the nature and scope of government activity on a local and regional basis. It could be a useful tool for advancing the proposals first made by the ABS and the CGC for ranking Indigenous need on a regional basis.

Clearly, a significant challenge will be allowing for an interface between this data on government activity and available data collections on Indigenous socioeconomic outcomes. I am not sure how widely OIPC are consulting in developing this tool-whether there is any discussion with Indigenous communities about it or whether it is being kept as internal to government. But there are the various concept papers and reports of the project on the OIPC web site. This project offers much potential in addressing some of the need that exists for better data.

In terms of disaggregation, there is a further process underway that may provide some ways forward. In this year's budget, the government announced a new 'Healthy for life' program totalling $\$ 113.6 \mathrm{~m}$ over the next five years. This initiative involves, among other things, the establishment of a number of 'healthy for life' sites providing primary health care interventions. Each site will be subject to a formal evaluation process and has benchmarks set for the life of the program. These include halving incidence of low-birth-weight babies within five years. My office will be interested to see how people collect the data to establish whether these benchmarks are met.

I also note that the budget included a measure titled 'Indigenous communities - developing a twenty-to-thirty-year vision'. This is intended to 'assist Indigenous communities to develop their long-term vision and aspirations

4 See: http://www.oipc.gov.au/AGIMIS/default.asp 
and identify what is required to achieve these goals'. The funding for this process is negligible - $\$ 1$ million for each of the next two years. I have no further information about the project. I do not know if this involves a detailed needs assessment and projection of community need in the context of population projections for individual communities, such as the work done by John Taylor in Wadeye (Taylor 2004b). This is something my office will also be interested to watch.

\section{Conclusion}

In conclusion, I know that I have probably raised more issues than I have provided answers for today. In particular, I have highlighted the importance of a benchmarking approach and an approach that is built on engagement and participation of Indigenous people at all stages of the process. My point is that we are currently a long way from this situation. We do not have a system for saying, when all variables and people's desires are taken into account, what is a reasonable and acceptable rate of progress. We do not have a system which identifies what is an acceptable Indigenous socioeconomic outcome and, hence, whether government is meeting its responsibilities well.

I will be providing some ways forward on this in my forthcoming Social Justice Report in terms of setting forward a twenty-year agenda for addressing health inequality. I hope this agenda will be the focus of debate and attention over the next twelve months.

But clearly, data collection is critical as a tool for accountability and for enhancing Indigenous participation. We need to work with government to improve the existing systems and to build on the initiatives they have in place. I hope that my contribution has emphasised how important these issues are and the priority that government should place on them.

But we also have to look beyond government. In a climate where the new arrangements are not fully locked into place and where issues such as data collection and monitoring and evaluation processes remain very much under development or consideration, it is incumbent on researchers, Non-Government Organisations and service deliverers to ask what we can do to supplement government processes and document and evidence the success or otherwise of these processes. There has never been a more important time for this research to occur. 